\title{
Smoking Relapse Situations among a Community-Recruited Sample of Spanish
}

\section{Daily Smokers}

\author{
Bárbara Piñeiro $^{\mathrm{a}^{*}}$, Ana López-Durán ${ }^{\mathrm{a}}$, Carmela Martínez-Vispo ${ }^{\mathrm{a}}$, \\ Elena Fernández del Ríob, Úrsula Martínez ${ }^{\mathrm{a}}$, Rubén Rodríguez-Cano ${ }^{\mathrm{a}}$, \\ M. Carmen Míguez ${ }^{\mathrm{a}}$, and Elisardo Becoña ${ }^{\mathrm{a}}$
}

${ }^{\mathrm{a}}$ Smoking Cessation and Addictive Disorders Unit, Department of Clinical Psychology and Psychobiology, Faculty of Psychology, Universidade de Santiago de Compostela, Galicia, Spain

${ }^{\mathrm{b}}$ Department of Psychology and Sociology, University of Zaragoza, Zaragoza, Spain

*Corresponding author: Bárbara Piñeiro, PhD., Smoking Cessation and Addictive Disorders Unit, Department of Clinical Psychology and Psychobiology, Faculty of Psychology, Universidade de Santiago de Compostela, Campus Universitario Vida, 15782, Santiago de Compostela, Galicia, Spain. Tel.: +34 881813 939. E-mail: barbara.pineiro@usc.es 


\begin{abstract}
Introduction: Relapse is a common factor within the behavior change process. However, there is scarce and limited knowledge of smoking relapse situations in population-based samples. The aim of this study was to identify smoking relapse situations among a sample of Spanish relapsers from the general population.

Methods: A sample of 775 relapsers was recruited among the general population using a snowball method. Participants completed a survey including sociodemographic, smoking-related and psychopathology variables. Smoking relapse situations were identified through specific questions assessing different aspects related to the last relapse episode.
\end{abstract}

Results: The majority of smoking relapse situations were attributed to positive affect (36.6\%) and negative affect (34.3\%), followed by lack of control (10.1\%), smoking habit $(6.7 \%)$, craving or nicotine withdrawal (6.3\%), and social pressure (5.9\%). Being unemployed and having a mental disorder in the past increased the likelihood of relapse in situations of negative affect. Being single and having quit smoking to save money were associated with an increased likelihood of relapse in situations of positive affect.

Conclusions: Affect plays a significant role in smoking relapse among a community sample of unassisted Spanish smokers. Relapse may be much more of an affective and situational process than a habit, physiological or social pressure. Findings from this study may help develop tailored community smoking relapse prevention strategies or programs.

Keywords: smoking, relapse, situations, Spanish, smokers, public health 


\section{Introduction}

Smoking is one of the most serious public health problems in developed countries. Despite a considerable decline in cigarette smoking in developed nations over the past several decades, smoking is still common (World Health Organization [WHO], 2015). In Spain, the prevalence of tobacco smoking decreased over the past 10 years from 32\% in 1993 to 24\% in 2013 (Spanish Ministry of Health, 2015). If tobacco control efforts continue at the same intensity, the WHO predicts that in 2025, around $21 \%$ of the Spanish population (approximately 8,528,400 persons) will be smokers. However, tobacco use continues to be the leading cause of preventable disease, general morbidity and mortality and health expenses in developed countries and reduction of cigarette smoking continues to be one of the highest public health priorities (WHO, 2015).

Most smokers make a number of quit attempts before becoming completely abstinent, making relapse a common factor within the behavior change process (e.g., Brandon, Vidrine, \& Litvin, 2007; Piasecki, 2006; Piñeiro \& Becoña, 2013). Despite the availability of quit aids, a vast majority of smokers report quitting or making a quit attempt on their own and not with assisted treatments (Edwards, Bondy, Callaghan, \& Mann, 2014; Smith, Carter, Chapman, Dunlop, \& Freeman, 2015), and it is significantly more difficult for smokers to achieve long-term abstinence from a given cessation attempt without such assisted treatments (Hughes, Keely, \& Naud, 2004). Even with evidence-based treatment (consisting of behavioral counseling and/or medication), only around $10 \%$ to $30 \%$ achieve long-term abstinence; a great majority eventually relapse. In fact, relapse or cessation failure is the common outcome of smoking cessation attempts (Fiore et al., 2008). These data reflect the fact that effective relapse prevention remains an unachieved goal of smoking treatment research (Hajek et al., 2013). 
Increased knowledge of the situations or determinants of relapse may hold the key to improved relapse prevention interventions.

Situations or determinants of smoking relapse after a quit attempt are well known, especially in clinical samples. For example, research on relapse has identified negative affectivity (anger, stress, anxiety, depression) with relapse (Brandon, Tiffany, Obremski, \& Baker, 1990; Shiffman \& Waters, 2004). Positive social experiences (e.g., socializing) have also been linked to relapse (Borland 1990; Japuntich et al., 2011). Craving and urges have also been found to trigger relapse (Killen \& Fortmann, 1997; Shiffman, Paty, Gnys, Kassel, \& Hickcox, 1996). Moreover, it is also known that the risk of relapse increases with greater exposure to other smokers at home, or in social or professional settings (Carlson, Taenzer, Koopmans, \& Bultz, 2000; Deiches, Baker, Lanza, \& Piper, 2013) and with higher nicotine dependence (Japuntich et al., 2011). However, despite the high prevalence of relapse, there is scarce and limited knowledge of smoking relapse situations in the general population of smokers (e.g., García-Rodriguez, et al., 2013; Herd, Borland, \& Hyland, 2009; Zhou et al., 2009). Nearly all the studies that identified predictors of smoking relapse were conducted with treatment-seeking smokers in clinical samples. Therefore, identifying those situations or contexts that influence individuals' smoking relapse in community-based studies remains a huge public health concern. A first step in understanding behavior change is to obtain an adequate description of it in its natural (i.e., untreated) state (Vaillant, 1983). Shiffman et al. (2002) made the first study of smoking antecedents in naturalistic settings with a large sample of smokers seeking smoking cessation treatment $(\mathrm{N}=304)$, finding that smoking is under partial control of situational antecedents (e.g., urge to smoke, alcohol or coffee consumption, smoking restrictions, social and sensory 
smoking cues), and that certain locations and activities were associated with enhanced likelihood of smoking.

There is strong evidence that situational or contextual factors play a major role in determining relapse occurrence and consequences. Unfortunately, relatively little research has been directed at understanding the nature of the contextual influences on relapsing in population-based samples. The current research sought to identify the smoking relapse situations among a sample of Spanish smokers from the general population. To our knowledge, this is the first study to examine the situations of relapse in this population. Understanding the situations of relapse among unassisted smokers in the general population may be important for understanding relapse mechanisms in its natural context. Such information could help develop tailored smoking relapse programs that reach entire community and not just smokers seeking treatment. This information will inform public health interventions to increase sustainable smoking cessation.

\section{Methods}

\subsection{Participants}

Participants in the current study were adult daily smokers recruited from the general population from two regions on the North of Spain (Galicia and Aragón) through a snowball sampling strategy in which respondents were asked to refer other smokers who might be willing to participate. Participants met the following criteria: (1) being 18 years of age or older, (2) smoking at least 10 cigarettes per day, (3) having smoked cigarettes in the last 10 years, (4) having reported a history of daily smoking for at least one year within the last 10 years, (5) having stopped smoking for at least one month in the past 5 years and having relapsed, and (6) smoking for at least one month at the time of data collection. 
Exclusion criteria included the following: (1) being abstinent, (2) having a diagnosis of a severe mental disorder (bipolar disorder and/or psychotic disorder) or cognitive deficits that prevent completing the questionnaire.

Of the 1017 participants assessed for eligibility, 775 met inclusion criteria and completed the survey.

\subsection{Measures}

\subsubsection{Survey instrument}

An anonymous self-administered pencil-and-paper questionnaire was used in this study. The questionnaire included closed and open-ended questions. Average completion time was approximately 10 minutes. Components of the survey that were analyzed in this study included the following:

\subsubsection{Sociodemographics}

The following demographic information was collected: age, gender, marital status, education, and employment status.

\subsubsection{Smoking variables}

Participants answered a series of questions about their past and current use of tobacco cigarettes including number of cigarettes smoked per day (CPD), age at the first cigarette, number of years smoking, reasons for quitting smoking in the past, method for smoking cessation, stages of change, nicotine dependence, and situations of smoking relapse.

Stages of change were assessed with the Stages of Change Questionnaire (Prochaska, Diclemente, \& Norcross, 1992). For the assessment of nicotine dependence, we used the Fagerström Test for Nicotine Dependence (FTND; Heatherton, Kozlowski, Frecker, \& Fagerström, 1991; Spanish version by Becoña \& Vázquez, 1998), a six-item 
scale with scores ranging from 0 to 10 . A score of 6 or more indicates high nicotine dependence. We also used a brief version of the Nicotine Dependence Syndrome Scale (NDSS-S; Shiffman, Waters, \& Hickcox, 2004; Spanish version by Becoña et al., 2011). This scale assesses nicotine dependence based on DSM-IV criteria. The NDSS-S is made up of 6 items with a Likert-type response format ranging from 1 (not true) to 5 (completely true). Total score on the scale ranged from 6 to 30, and the cut-off point for nicotine dependence was 11 or above, according to criteria of sensitivity (.87) and specificity (.37) indicated by the authors (see Becoña et al., 2011).

\subsubsection{Smoking relapse situations}

Smoking relapse situations were identified with specific questions about various aspects related to the last relapse episode, following the more relevant relapse models (Marlatt \& Donovan, 2005; Marlatt \& Gordon, 1985; Shiffman, 2005; Velicer, Diclemente, Rossi, \& Prochaska, 1990). Participants were asked: "Focusing on your last attempt to quit smoking, how did the relapse occur?", "Where were you?", "What were you doing?", "Was anyone else smoking?", and "Were you drinking coffee or alcohol?"

Relapse situations were coded in six categories by two psychologists trained in this process: 1) positive affect (PA), 2) negative affect (NA), 3) lack of control, 4)

smoking habit, 5) craving or nicotine withdrawal syndrome, and 6) social pressure. The categories were created by researchers based on previous literature about relapse models. We considered each answer of the participant as mutually exclusive allowing only the identification of just one relapse category. Table 1 shows the description of each category of relapse.

\subsubsection{Psychopathology}


Participants were asked if they were diagnosed with a mental disorder in the past or in the present, and more specifically, whether they were diagnosed with depression. They were also asked about their current use of psychoactive drugs.

\subsection{Procedure}

Participants were recruited between 2013 to 2015 with the snowball sampling method starting from undergraduate and postgraduate psychology students at the University of Santiago de Compostela (Galicia) and the University of Zaragoza (Aragón). Subsequently, the sample was enhanced using a snowball method by asking respondents if they knew other smokers who may wish to participate in the study. We used the snowball sampling method because this technique has been used to contact hard-to-reach populations in studies using face-to-face interviews (Willems, Iguchi, Lidz, \& Bux, 1997). Due to our specific inclusion criteria, it was very difficult to recruit this population, and as Etter \& Perneger (2000) pointed out the snowball method doubled the response rate and is a cost-effective method of data collection; therefore, we opted to use this recruitment method. Participation in the study was voluntary, and participants were not compensated for being included in the study. The study was approved by the Bioethics Committee of the University of Santiago de Compostela.

\subsection{Data Analysis}

A descriptive statistical analysis was made of the total sample $(N=775)$.

Differences between smoking relapse situations and sociodemographic, smoking-related and psychopathology variables were determined using a chi-square test for categorical variables. Given the sample size, the tables include Cramer's $V$ effect size for significant chi-squared results. Cramer's $V$, is an effect size or a measure of association, used to measure the strength of the association between one nominal variable with either another nominal variable, or with an ordinal variable. Effect sizes, or measures of 
association, reveal the differences in data regardless of sample size. They demonstrate practical or meaningful differences, rather than simply statistical differences. Cramer's $V$ range labels were small: $(\leq 0.2)$, medium $(0.3-0.5)$, and large $(\geq 0.6)$ (Cohen, 1988). Standard logistic regression analyses were conducted with the variables that were significant in the bivariate analysis to determine odds of smoking relapse situations of negative and positive affect. All analyses were conducted with SPSS version 20.0, with a $p$-value of less than .05 considered significant.

\section{Results}

\subsection{Sample characteristics}

The sample of 775 relapsers from the general population included $363(46.8 \%)$ males and $412(53.2 \%)$ females, with a mean age of 42 years $(S D=10.83$; range $23-85$ years). Table 2 presents sociodemographic, smoking, and psychopathology characteristics of the sample. More than half (59\%) of the participants were married or living with a partner, approximately half (42\%) had some high school or general education diploma, and the majority were employed at the time of completing the survey $(72 \%)$.

Participants smoked a mean of 15.60 CPD $(S D=6.49$; range 10-60), mean age at the first cigarette was 15.53 years $(S D=2.91)$, and they had been smoking an average of 23.85 years $(S D=10.46)$. One half $(50.5 \%)$ of the smokers reported being in the contemplation stage of change. Most of the smokers (83.2\%) were non-nicotine dependent according to the FTND $(<6)$; however, according to the NDSS-S, more than half of the smokers (68.1\%) were dependent. Most of the smokers (78\%) reported not having followed any specific formal method to quit smoking in their previous attempts of quitting in the past, and $29 \%$ of the smokers responded that their doctor had never suggested they should quit smoking. Regarding reasons to quit smoking in the past, the 
most frequently reported reasons included concern about health $(54.5 \%)$, to cease tobacco dependence $(40.4 \%)$, to save money $(39.9 \%)$ and fear of the diseases caused by tobacco $(32.3 \%)$. Regarding psychopathology variables, 19\% had been in treatment for depression at some time, and $6.2 \%$ reported currently consuming psychoactive drugs.

\subsection{Smoking relapse situation characteristics}

The majority of the smoking relapse situations were attributed to PA (36.6\%) and NA (34.3\%), followed by lack of control (10.1\%), smoking habit $(6.7 \%)$, craving or nicotine withdrawal syndrome $(6.3 \%)$ and social pressure $(5.9 \%)$.

\subsection{Bivariate analyses}

In order to simplify the presentation and the interpretation of the results, we used 3 categories for the bivariate analyses: the main categories of affect (positive and negative) and others, where we grouped the rest of the categories of less frequent relapse situations. There were differences between the three categories of relapse in sociodemographic, smoking and psychopathology characteristics (see Table 3).

Smoking relapse in situations of NA were more likely if participants were divorced/separated/widowed, unemployed, had suffered a mental disorder in the past or suffered it currently, consumed psychoactive drugs, had reduced their cigarette consumption in the past year, were nicotine dependent, used a method to quit smoking and, their doctor had many times recommended to quit smoking compared to smoking relapse in situations of PA and others.

Smoking relapse in situations of PA were more likely if participants were 40 or younger, single, had been smoking for less than 20 years, their reason to quit smoking was to save money and, their doctor had never recommended to quit smoking compared to smoking relapse in situations of others. 
Smoking relapse in Other situations were more likely if participants were older than 40 years, married or living with a partner, employed, had been smoking more than 20 years and, their doctor had sometimes recommended to quit smoking.

\subsection{Predictors of smoking relapse in situations of negative affect and positive affect}

To examine predictors of smoking relapse in NA and PA situations, two binary standard logistic regression analyses were performed with the variables that were significant in the bivariate analysis (see Table 4). Regarding the variables that predict relapse in NA situations, we found that being unemployed $(O R=1.53)$, and having suffered a mental disorder in the past $(O R=2.66)$ increased the likelihood of relapse. Conversely, being married or living with a partner $(\mathrm{OR}=0.57)$, the fact that their doctor had never recommended smoking cessation $(O R=0.64)$, and not reporting quit smoking to save money as a reason $(O R=0.71)$ decreased the likelihood of relapse in situations of NA.

Regarding relapse situations due to $\mathrm{PA}$, being single $(O R=1.36)$, and having quit smoking to save money $(O R=1.62)$ increased the likelihood of relapse.

\section{Discussion}

The current study sought to identify smoking relapse situations among Spanish smokers recruited from the community. The results indicate that the majority of relapses occur in situations of positive and negative affect (70\%), consistent with previous research that showed a strong link between affect and relapse (e.g., Shiffman et al., 2002; Shiffman et al., 1996). Both negative and positive affect have been proposed as important triggers for smoking, and most theories of smoking emphasize the role of affect in driving smoking (Shiffman et al., 2002; Shiffman \& Waters, 2004).

Consistent with previous studies in the general population (García-Rodriguez et al., 2013; Herd et al., 2009; Zhou et al., 2009), we found that some sociodemographic, 
smoking-related and psychopathology variables predicted increased risk of relapse in certain contexts or situations. For example, we found that being single, and having quit smoking to save money were associated with an increased likelihood of relapse in situations of PA. The likelihood of relapse in situations of PA may be related to a lifestyle associated with greater exposure to high-risk situations (Japuntich et al., 2011; Shiffman et al., 2002; Shiffman et al., 1996). For example, single people have the likelihood of being younger and in celebratory situations where alcohol is consumed. In fact, Deiches et al. (2013) have recently found that young smokers lapsed while talking and drinking with friends out a bar or restaurant. In addition, Herd et al. (2009) found that the number of close friends who smoked predicted relapse in the first month after quitting. To prevent relapse in situations of PA, smokers may benefit from advice to avoid other smokers, parties, and alcohol for at least the first week after quitting smoking, when withdrawal symptoms tend to peak. Stronger smoking bans in public places are also beneficial (Shiffman et al., 2002; Shiffman et al., 1996; Trotter, Wakefield, \& Borland, 2002). Moreover, tobacco tax increases, public health campaigns, and tobacco-education campaigns that promote healthier leisure activities (Fiore, 2016) may help to prevent relapse due to PA.

On the contrary, the results showed that being unemployed, and having suffered a mental disorder in the past increased the likelihood of relapse in situations of NA. The findings that situations of NA are contexts for relapse is consistent with research that associates negative affect with a higher likelihood of relapse (Brandon et al., 1990; Shiffman et al., 2002; Shiffman \& Waters, 2004). Our data show that smokers who had a mental disorder in the past are more likely to relapse in situations of NA. Therefore, smoking relapse prevention programs or strategies should target populations at a high risk of relapse (e.g., adults and youth with mental disorder and nicotine dependence). 
One way to reach such groups is through efforts that directly affect the scope of services and facilities serving those populations. Such efforts include tobacco-free policies, quitline promotion, counseling and cessation services in places like mental health facilities (U.S.D.H.H.S., 2010). Therefore, it is of vital importance for the clinicians or GPs to know how to give advice to help people to quit smoking and prevent the relapse of smokers who visit the doctor for these types of diseases (West et al., 2015).

Most of the sample, nearly $80 \%$, reported having tried to quit smoking without any type of help (unassisted smoking cessation), in line with the findings in the literature (Edwards et al., 2014; Smith et al., 2015). As Smith and colleagues pointed out, cultural values are likely to play a role in the choice to use or not use assistance, and future research should explore these issues in other cultures. In addition, GarcíaRodríguez et al. (2013) suggested that community studies are needed to examine the role of the community in relapse in non-clinical samples. This highlights the need for longitudinal research using population-representative samples to describe who is trying to quit unassisted, who succeeds, and what predicts success in this group or who relapses and what predicts the relapse.

This study has some limitations. Possible recall bias limits the interpretability of this study; in fact, the long recall period between the relapse and the day of the interview allows for potential recall bias (Gilpin \& Pierce, 1994). However, even though retrospective reporting has been criticized, studies that use ecological momentary assessment (EMA), indicating that precipitants identify with this methodology, are consistent with reported retrospective recall findings (Shiffman \& Waters, 2004). In addition, causality cannot be inferred from our findings. Another possible limitation is that our sample may not be representative of the general population of smokers because of the recruitment method used, this may have 
introduced some bias as recruitment was not random. Despite these limitations, the strengths of this study are the large sample size of relapsers, from all educational levels, employment statuses, and the inclusion of the entire population of smokers at the stages of change: precontemplation, contemplation, and preparation, and not just those at the preparation stage. Our study is also important, particularly because recommendations for assisted methods for smoking cessation and relapse prevention are based on evidence from clinical trials, which typically include heavier smokers and smokers who are motivated both to quit and to seek help, excluding an estimated 6 out of 10 current smokers in the general population (Le Strat, Rehm, \& Le Foll, 2011), and we examine situations of relapse in a population-based sample in the natural context among smokers quitting on their own.

Findings from this study suggest that the smoking relapse behavior of a large proportion of a community sample of unassisted Spanish smokers is influenced by positive and negative events. These findings add to the literature that relapse may be much more of an affective and situational process among smokers than a habit, or a physiological or social pressure, similar to what has been found in a recent study using dataset of four population-based studies (Gökbayrak, Paiva, Blissmer, \& Prochaska, 2015). Our study may help develop more targeted and effective relapse prevention programs among community samples of Spanish smokers, with the potential to reach entire communities of smokers and not only smokers who are seeking treatment.

\section{References}

Becoña, E., Fernández del Rio, E., López, A., Míguez, M. C., Castro, J., Nogueiras, L., ... Vázquez, D. (2011). La escala breve de evaluación del Síndrome de Dependencia de la Nicotina (NDSS-S) en fumadores españoles [The Short 
Nicotine Dependence Syndrome Scale (NDSS-S) in Spanish smokers]. Psicothema, 23(1), 126-132.

Becoña, E., \& Vázquez, F. L. (1998). The Fagerström Test for Nicotine Dependence in a Spanish sample. Psychological Reports, 83(3), 14551458.doi:10.2466/pr0.1998.83.3f.1455.

Borland, R. (1990). Slip-ups and relapse in attempts to quit smoking. Addictive Behaviors, 15(3), 235-245. doi:10.1016/0306-4603(90)90066-7.

Brandon, T. H., Tiffany, S. T., Obremski, K. M., \& Baker, T. B. (1990). Postcessation cigarette use: The process of relapse. Addictive Behaviors, 15(2), 105-114. doi:10.1016/0306-4603(90)90013-N.

Brandon, T. H., Vidrine, J. I., \& Litvin, E. B. (2007). Relapse and relapse prevention. Annual Review of Clinical Psychology, 3, 257-284. doi:10.1146/annurev.clinpsy.3.022806.091455.

Carlson, L. E., Taenzer, P., Koopmans, J., \& Bultz, B. D. (2000). Eight-year follow-up of a community-based large group behavioral smoking cessation intervention. Addictive Behaviors, 25(5), 725-741. doi:10.1016/S0306-4603(00)00081-2.

Cohen, J. (1988). Statistical power analysis for the behavioral sciences. Hillsdale, NJ: Erlbaum.

Deiches, J. F., Baker, T. B., Lanza, S., \& Piper, M. E. (2013). Early lapses in a cessation attempt: Lapse contexts, cessation success, and predictors of early lapse. Nicotine \& Tobacco Research, 15(11), 1883-1891. doi:10.1093/ntr/ntt074.

Edwards, S. A., Bondy, S. J., Callaghan, R. C., \& Mann, R. E. (2014). Prevalence of unassisted quit attempts in population-based studies: A systematic review of the literature. Addictive Behaviors, 39(3), 512-19. doi:10.1016/j.addbeh.2013.10.036. 
Etter, J. F., \& Perneger, T. V. (2000). Snowball sampling by mail: Application to a survey of smokers in the general population. International Journal of Epidemiology, 29(1), 43-48. doi:10.1093/ije/29.1.43

Fiore, M. C. (2016). Tobacco control in the Obama era-Substantial progress, remaining challenges. The New England Journal of Medicine, 375(15), 1410-1412. doi:10.1056/NEJMp1607850.

Fiore, M. C., Jaén, C. R., Baker, T. B., Bailey, W. C., Benowitz, N. L., Curry, S. J., ... Wewers, M. E. (2008). Treating tobacco use and dependence: 2008 update. Clinical practice guideline. Rockville, MD: U. S. Department of Health and Human Services, Public Health Service.

Garcia-Rodriguez, O., Secades-Villa, R., Florez-Salamanca, L., Okuda, M., Liu, S. M., \& Blanco, C. (2013). Probability and predictors of relapse to smoking: Results of the National Epidemiologic Survey on Alcohol and Related Conditions (NESARC). Drug \& Alcohol Dependence, 132(3), 479-485. doi:10.1016/j.drugalcdep.2013.03.008.

Gilpin, E., \& Pierce, J. P. (1994). Measuring smoking cessation: Problems with recall in the 1990 California Tobacco Survey. Cancer Epidemiology, Biomarkers, \& Prevention, 3(7), 613-617.

Gökbayrak, N. S., Paiva, A. L., Blissmer, B. J., \& Prochaska, J. O. (2015). Predictors of relapse among smokers: Transtheoretical effort variables, demographics, and smoking severity. Addictive Behaviors, 42, 176-179. doi:10.1016/j.addbeh.2014.11.022.

Hajek P., Stead L. F., West R., Jarvis M., Hartmann-Boyce J., \& Lancaster T. (2013). Relapse prevention interventions for smoking cessation. Cochrane Database of Systematic Reviews, 8, CD003999. doi:10.1002/14651858.CD003999.pub4. 
Heatherton, T. F., Kozlowski, L. T., Frecker, R. C., \& Fagerström,K. O. (1991). The Fagerström Test for Nicotine Dependence: A revision of the Fagerström Tolerance Questionnaire. British Journal of Addiction, 86(9), 1119-1127. doi:10.1111/j.1360-0443.1991.tb01879.x.

Herd, N., Borland, R., \& Hyland, A. (2009). Predictors of smoking relapse by duration of abstinence: Findings from the International Tobacco Control (ITC) Four Country Survey. Addiction, 104(12), 2088-2099. doi:10.1111/j.13600443.2009.02732.x.

Hughes J. R., Keely J., \& Naud S. (2004). Shape of the relapse curve and long-term abstinence among untreated smokers. Addiction, 99(1), 29-38. doi:10.1111/j.1360-0443.2004.00540.x.

Japuntich, S. J., Leventhal, A. M., Piper, M. E., Bolt, D. M., Roberts, L. J., Fiore, M. C., \& Baker, T. B. (2011). Smoker characteristics and smoking-cessation milestones. American Journal of Preventive Medicine, 40(3), 286-294. doi:10.1016/j.amepre.2010.11.016.

Killen, J. D., \& Fortmann, S. P. (1997). Craving is associated with smoking relapse: Findings from three prospective studies. Experimental and Clinical Psychopharmacology, 5(2), 137-142. doi:10.1037/1064-1297.5.2.137.

Le Strat, Y., Rehm, J., \& Le Foll, B. (2011). How generalisable to community samples are clinical trial results for treatment of nicotine dependence: A comparison of common eligibility criteria with respondents of a large representative general population survey. Tobacco Control, 20(5), 338-343.

doi:10.1136/tc.2010.038703.

Marlatt, G. A., \& Donovan, D. M. (2005). Relapse prevention: Maintenance strategies in the treatment of addictive behaviors ( $2^{\text {nd }}$ ed.). New York, NY: Guilford Press. 
Marlatt, G. A., \& Gordon, J. R. (Eds.). (1985). Relapse prevention: Maintenance strategies in the treatment of addictive behaviors. New York, NY: Guilford Press.

Piasecki, T. M. (2006). Relapse to smoking. Clinical Psychology Review, 26(2), 196215. doi:10.1016/j.cpr.2005.11.007.

Piñeiro, B., \& Becoña, E. (2013). Relapse situations according to Marlatt's taxonomy in smokers. The Spanish Journal of Psychology, 16, E91. doi:10.1017/sjp.2013.91.

Prochaska, J.O., Diclemente, C.C., \& Norcross, J.C. (1992). In search of how people change. Applications in addictive behaviors. American Psychologist, 47(9), 1102-1114. doi :10.1037/0003-066X.47.9.1102.

Shiffman, S. (2005). Dynamic influences on smoking relapse process. Journal of Personality, 73(6), 1715-1748. doi:10.1111/j.0022-3506.2005.00364.x.

Shiffman, S., Gwaltney, C. J., Balabanis, M. H., Liu, K. S., Paty, J. A., Kassel, J. D., ...Gnys, M. (2002). Immediate antecedents of cigarette smoking: An analysis from ecological momentary assessment. Journal of Abnormal Psychology, 111(4), 531-545. doi:10.1037/0021-843X.111.4.531.

Shiffman, S. M., Paty, J. A., Gnys, M., Kassel, J. A., \& Hickcox, M. (1996). First lapses to smoking: Within-subjects analysis of real-time reports. Journal of Consulting and Clinical Psychology, 64(2), 366-379. doi:10.1037/0022-006X.64.2.366.

Shiffman, S., \& Waters, A. J. (2004). Negative affect and smoking lapses: A prospective analysis. Journal of Consulting and Clinical Psychology, 72(2), 192201. doi:10.1037/0022-006X.72.1.192.

Shiffman, S., Waters, A. J., \& Hickcox, M. (2004). The Nicotine Dependence Syndrome Scale: A multidimensional measure of nicotine dependence. Nicotine \& Tobacco Research, 6(2), 327-348. doi:10.1080/1462220042000202481. 
Smith, A. L., Carter, S. M., Chapman, S., Dunlop, S.M., \& Freeman, B. (2015). Why do smokers try to quit without medication or counselling? A qualitative study with ex-smokers. BMJ Open, 5(4), e007301. doi:10.1136/bmjopen-2014007301.

Spanish Ministry of Health (2015). Encuesta sobre alcohol y drogas en España EDADES 2013-2014. [Spanish National Survey about alcohol and drugs: EDADES 2013-

2014].http://www.pnsd.msssi.gob.es/ca/profesionales/sistemasInformacion/siste maInformacion/encuestas_EDADES.htm. Accessed September 4, 2016

Trotter, L., Wakefield, M., \& Borland, R. (2002). Socially cued smoking in bars, nightclubs, and gaming venues: A case for introducing smoke-free policies. Tobacco Control, 11(4), 300-304. doi:10.1136/tc.11.4.300.

U.S. Department of Health and Human Services. (2010). Ending the tobacco epidemic: A tobacco control strategic action plan for the U.S. Department of Health and Human Services. Washington, DC: Office of the Assistant Secretary for Health. Vaillant, G. E. (1983). The natural history of alcoholism. Cambridge, MA: Harvard University Press.

Velicer, W. F., Diclemente, C. C., Rossi, J. S., \& Prochaska, J. O. (1990). Relapse situations and self-efficacy: An integrative model. Addictive Behaviors, 15(3), 271-283. doi:10.1016/0306- 4603(90)90070-E

West, R., Raw, M., McNeill, A., Stead, L., Aveyard, P., Bitton, J., . . Borland, R. (2015). Health-care interventions to promote and assist tobacco cessation: A review of efficacy, effectiveness and affordability for use in national guideline development. Addiction, 110(9), 1388-1403. doi:10.1111/add.12998.

Willems, J. C., Iguchi, M. Y., Lidz, V., \& Bux, D. A., Jr. (1997). Change in drug-using networks of injecting drug users during methadone treatment: A pilot study 
using snowball recruitment and intensive interviews. Substance Use \& Misuse, 32(11), 1539-1554.

World Health Organization. (2015). WHO global report on trends in prevalence of tobacco smoking 2015. Geneva, Switzerland: World Health Organization.

Zhou, X., Nonnemaker, J., Sherrill, B., Gilsenan, A., Coste, F., \& West, R. (2009). Attempts to quit smoking and relapse: Factors associated with success or failure from the ATTEMPT cohort study. Addictive Behaviors, 34(4), 365-373. doi:10.1016/j.addbeh.2008.11.013.

Zhu, S. H., Lee, M., Zhuang Y. L, Gamst, A., \& Wolfson T. (2012). Interventions to increase smoking cessation at the population level: How much progress has been made in the last two decades? Tobacco Control, 21(2), 110-118. doi:10.1136/tobaccocontrol-2011-050371. 
Table 1. Description of smoking relapse situations coded in six categories.

1. Positive Affect Celebrations, parties, lunches and dinners with friends, meetings with friends, being in the bar with friends, eating/drinking something with friends, drinking alcohol and coffee, on holiday

2. Negative Affect Stress, anxiety, anger, problems, worries, arguments, boredom, depression, weight problems

3. Lack of Control Just one cigarette does not matter; try one cigarette; ask for a cigarette; loss of motivation to be abstinent; when noticing physical improvements

4. Smoking Habit Conditioning or routine: e.g., after lunch, after dinner, after weaning and/or after giving birth, watching TV

5. Craving or Nicotine Desire, craving, sudden urge to smoke, weakness, and nicotine Withdrawal Syndrome withdrawal symptoms (addiction, dependence)

6. Social Pressure Being around other smokers, accepting the offer of cigarettes 
Table 2. Sociodemographic, smoking-related and psychopathology characteristics of total sample, $N=775$.

\begin{tabular}{|c|c|c|}
\hline & \multicolumn{2}{|c|}{$\begin{array}{c}\text { Total sample } \\
\mathrm{N}=775\end{array}$} \\
\hline & Mean/n & $(\mathrm{SD} / \%)$ \\
\hline Age (years) & 42.01 & $(10.8)$ \\
\hline \multicolumn{3}{|l|}{ Gender } \\
\hline Male & 363 & $(46.8)$ \\
\hline Female & 412 & $(53.2)$ \\
\hline \multicolumn{3}{|l|}{ Marital status } \\
\hline Single & 232 & (29.9) \\
\hline Married/living with a partner & 454 & $(58.6)$ \\
\hline Divorced/separated/widowed & 89 & (11.5) \\
\hline \multicolumn{3}{|l|}{ Education } \\
\hline$<$ HS diploma & 175 & (22.6) \\
\hline HS diploma or GED & 328 & $(42.3)$ \\
\hline College or technical school & 272 & (35.1) \\
\hline \multicolumn{3}{|l|}{ Current work situation } \\
\hline Working & 561 & (72.4) \\
\hline Unemployed & 214 & $(27.6)$ \\
\hline Number of cigarettes smoked per day & 15.60 & $(6.5)$ \\
\hline Age at first cigarette & 15.53 & (2.9) \\
\hline Years smoking & 23.85 & (10.5) \\
\hline \multicolumn{3}{|l|}{ FTND } \\
\hline Not dependent $(<6)$ & 645 & $(83.2)$ \\
\hline Dependent $(\geq 6)$ & 130 & $(16.8)$ \\
\hline \multicolumn{3}{|l|}{ NDSS-S } \\
\hline Not dependent $(<11)$ & 247 & (31.9) \\
\hline Dependent $(\geq 11)$ & 528 & $(68.1)$ \\
\hline \multicolumn{3}{|l|}{ Stages of change } \\
\hline Pre-contemplation & 319 & $(41.2)$ \\
\hline Contemplation & 391 & $(50.5)$ \\
\hline Preparation for action & 65 & $(8.4)$ \\
\hline \multicolumn{3}{|l|}{$\begin{array}{l}\text { In your attempts to quit smoking, did you follow a specific } \\
\text { procedure? }\end{array}$} \\
\hline Yes & 173 & $(22.3)$ \\
\hline No & 602 & (77.7) \\
\hline \multicolumn{3}{|l|}{ When you quit smoking, what was the main reason for quitting? } \\
\hline Health & 422 & (54.5) \\
\hline Fear of diseases caused by tobacco & 250 & $(32.3)$ \\
\hline Saving money & 309 & (39.9) \\
\hline Cease depending on tobacco & 313 & (40.4) \\
\hline \multicolumn{3}{|l|}{ Did your doctor ever suggest that you should quit smoking? } \\
\hline Never & 224 & (28.9) \\
\hline Sometimes & 389 & $(50.3)$ \\
\hline Many times & 162 & (20.9) \\
\hline Have you been in treatment for depression in the past 12 months? Yes & 45 & $(5.8)$ \\
\hline Have you ever suffered some mental disorder in the past? Yes & 35 & (4.5) \\
\hline Do you currently suffer some mental disorder? Yes & 24 & (3.1) \\
\hline Do you currently consume psychoactive drugs? Yes & 48 & $(6.2)$ \\
\hline
\end{tabular}

Note. $\mathrm{HS}=$ high school; GED = general education diploma; FTND = Fagerström Test for Nicotine Dependence; NDSS-S = Nicotine Dependence Syndrome Scale-Short. 
Table 3. Differences between significant sociodemographic, psychopathology, and smoking-related variables by smoking relapse situations, $N=$ 775 .

\begin{tabular}{|c|c|c|c|c|c|c|}
\hline & $\begin{array}{r}\text { NA } \\
\mathrm{n}(\%)\end{array}$ & $\begin{array}{r}\text { PA } \\
\mathrm{n}(\%)\end{array}$ & $\begin{array}{r}\text { Others }^{\mathrm{a}} \\
\mathrm{n}(\%)\end{array}$ & $\chi^{2}$ & $p$ & Cramer's $V$ \\
\hline Age & & & & $10.34^{1,3}$ & .006 & 0.12 \\
\hline$\leq 40$ years old & $119(44.7)$ & $153(53.9)$ & $90(40.0)$ & & & \\
\hline$>40$ years old & $147(55.3)$ & $131(46.1)$ & $135(60.0)$ & & & \\
\hline Marital status & & & & $35.04^{1,2,3}$ & .001 & 0.15 \\
\hline Single & $76(28.6)$ & $114(40.1)$ & $42(18.7)$ & & & \\
\hline Married/living with a partner & $148(55.6)$ & $149(52.5)$ & $157(69.8)$ & & & \\
\hline Divorced/separated/widowed & $42(15.8)$ & $21(7.4)$ & $26(11.6)$ & & & \\
\hline Current work situation & & & & $11.61^{2}$ & .003 & 0.13 \\
\hline Employed & $175(65.8)$ & $207(72.9)$ & $179(79.6)$ & & & \\
\hline Unemployed & $91(34.2)$ & $77(27.1)$ & $46(20.4)$ & & & \\
\hline Suffered mental disorder in the past (Yes) & $23(8.6)$ & $6(2.1)$ & $6(2.7)$ & $16.11^{1,2}$ & .001 & 0.14 \\
\hline Currently suffers mental disorder (Yes) & $14(5.3)$ & $6(2.1)$ & $4(1.8)$ & $6.38^{1,2}$ & .041 & 0.09 \\
\hline Use of psychoactive drugs (Yes) & $28(10.5)$ & $8(2.8)$ & $12(5.3)$ & $14.46^{1,2}$ & .001 & 0.14 \\
\hline Number of years smoking & & & & $8.62^{3}$ & .013 & 0.11 \\
\hline 20 years or less & $120(45.1)$ & $143(50.4)$ & $84(37.3)$ & & & \\
\hline More than 20 years & $146(54.9)$ & $141(49.6)$ & $141(62.7)$ & & & \\
\hline Reduced cigarette consumption in the past year (Yes) & $112(42.1)$ & $114(40.1)$ & $69(30.7)$ & $7.59^{2,3}$ & .023 & 0.10 \\
\hline NDSS-S & & & & $6.57^{1,2}$ & .038 & 0.09 \\
\hline Not dependent $(<11)$ & $69(25.9)$ & $99(34.9)$ & $79(35.1)$ & & & \\
\hline Dependent $(\geq 11)$ & $197(74.1)$ & $185(65.1)$ & $146(64.9)$ & & & \\
\hline Used procedure to quit smoking & $73(27.4)$ & $50(17.6)$ & $50(22.2)$ & $7.67^{1}$ & .022 & 0.10 \\
\hline Reasons to quit smoking: Saving money & $98(36.8)$ & $133(46.8)$ & $78(34.7)$ & $9.30^{1,3}$ & .010 & 0.11 \\
\hline Doctor had recommended to quit smoking & & & & $11.09^{2}$ & .026 & 0.09 \\
\hline Never & $67(25.2)$ & $90(31.7)$ & $67(29.8)$ & & & \\
\hline Sometimes & $127(47.7)$ & $140(49.3)$ & $122(54.2)$ & & & \\
\hline Many times & $72(27.1)$ & $54(19.0)$ & $36(16.0)$ & & & \\
\hline
\end{tabular}

Note. $\mathrm{NA}=$ negative affect; $\mathrm{PA}=$ positive affect

${ }^{a}$ Others: lack of control; smoking habit; craving or nicotine withdrawal syndrome; social pressure.

1 significant difference between NA and PA

${ }^{2}$ significant differences between NA and Others

${ }^{3}$ significant differences between PA and Others 
Table 4. Logistic regression analysis output as predictors of relapse situations of negative affect and positive affect.

\begin{tabular}{lrrrrrr}
\hline & \multicolumn{1}{c}{ B } & Wald & $p$ value & OR & \multicolumn{2}{c}{$95 \%$ CI } \\
\hline Negative Affect $^{a}$ & & & & & & \\
Marital status (married or living together) & -0.57 & 5.22 & .022 & 0.57 & 0.35 & 0.92 \\
Work situation (unemployed) & 0.42 & 5.86 & .016 & 1.53 & 1.08 & 2.16 \\
Past mental disorder (yes) & 0.98 & 5.59 & .018 & 2.66 & 1.18 & 5.98 \\
Reason to quit smoking (saving money) & -0.34 & 4.08 & .043 & 0.71 & 0.51 & 0.99 \\
Doctor suggested to quit smoking (never) & -0.46 & 3.89 & .048 & 0.64 & 0.41 & 0.99 \\
Constant & -0.90 & 3.90 & .048 & 0.41 & & \\
Positive Affect & & & & & & \\
Marital status (single) & 1.08 & 11.96 & .001 & 1.36 & 0.73 & 2.55 \\
Reason to quit smoking (saving money) & 0.48 & 8.88 & .003 & 1.62 & 1.18 & 2.23 \\
Constant & -2.30 & 10.16 & .001 & 0.10 & & \\
\hline
\end{tabular}

Note. $\mathrm{OR}=$ odd ratio; $\mathrm{CI}=$ confidence interval.

${ }^{\text {a}}$ Relapse situations of negative affect coded by 1 ; Relapse situations of positive affect and other situations coded by 0 .

${ }^{\mathrm{b}}$ Relapse situations of positive affect coded by 1 ; Relapse situations of negative affect and other situations coded by 0 . 


\section{Role of Funding Sources}

This work was supported by the Spanish Ministry of Economy and Competiveness (Ministerio de Economía y Competitividad) under Project reference: PSI2012-31196; the European Regional Development Fund (ERDF); and the Xunta de Galicia under Postdoctoral Training Grant, Galician Program for Research, Innovation and Growth 2011-2015 (I2C Plan), modality A.

\section{Contributors}

EB, ALD, and EFR designed the study. EB, ALD, EFR, CMV, and UM were involved in development of the questionnaire. EB, BP, ALD, CMV, EFR, RRC, conducted literature searches, statistical analysis and provided summaries of previous research. BP wrote the first draft of the manuscript and all authors contributed to and have approved the final manuscript. All authors had full access to the data.

\section{Conflict of Interest}

All authors declare that they have no conflicts of interest.The authors alone are responsible for the content and writing of the article. Spanish Ministry of Economy and Competiveness (Ministerio de Economía y Competitividad) had no role in the study design, collection, analysis or interpretation of the data, writing the manuscript, or the decision to submit the paper for publication. 
Behaviors

Elsevier Editorial System(tm) for Addictive Manuscript Draft

Manuscript Number: ADDICTBEH-D-17-00053R1

Title: Smoking Relapse Situations among a Community-Recruited Sample of Spanish Daily Smokers

Article Type: Full Length Article

Keywords: smoking; relapse; situations; Spanish; smokers; public health Corresponding Author: Dr. Bárbara Piñeiro, Ph.D

Corresponding Author's Institution: University of Santiago de Compostela

First Author: Bárbara Piñeiro, Ph.D

Order of Authors: Bárbara Piñeiro, Ph.D; Ana López-Durán, Ph.D; Carmela Martínez-Vispo, M.A.; Elena Fernández del Río, Ph.D; Úrsula Martínez, Ph.D; Rubén Rodríguez-Cano, M.A.; M.Carmen Míguez, Ph.D; Elisardo Becoña, $\mathrm{Ph} . \mathrm{D}$ 


\section{Highlights}

- We identify smoking relapse situations among a community sample of Spanish smokers

- The majority of relapses occur in situations of positive and negative affect

- Relapses in situations of positive affect may be related to recreational contexts

- Negative life events are associated with relapse in situations of negative affect

- Most of the sample reported having tried to quit smoking unassisted

- Tailored community smoking relapse prevention programs are needed 